\title{
Long-Term Prognosis of Dilated Cardiomyopathy Revisited An Improvement in Survival Over the Past 20 Years
}

\author{
Yoshihisa Matsumura, MD; Jun Takata, MD; Hiroaki Kitaoka, MD; Toru Kubo, MD; \\ Yuichi Baba, MD; Eri Hoshikawa, MD; Tomoyuki Hamada, MD; Makoto Okawa, MD; \\ Nobuhiko Hitomi, MD; Kyoko Sato, MD; Naohito Yamasaki, MD; Toshikazu Yabe, MD; \\ Takashi Furuno, MD; Masanori Nishinaga, MD; Yoshinori Doi, MD
}

\begin{abstract}
Background Because of their favorable prognostic effects, angiotensin converting enzyme inhibitors (ACEI), angiotensin II receptor blockers (ARB) and $\beta$ blockers have become background therapy in dilated cardiomyopathy (DCM). However, there are few reports concerning the long-term prognosis of Japanese patients with DCM in relation to these treatments.

Methods and Results One hundred and fifty patients with DCM were divided into 2 groups: group A ( $\mathrm{n}=46$ ) (diagnosis: 1982-1989) and group B (n=104) (diagnosis: 1990-2002). During follow-up period of 6.9 \pm 4.8 years, 62 patients died and 1 patient had a heart transplant. The survival rate at 5 and 10 years was $60.9 \%$ and $34.8 \%$, respectively, in group A patients, and $80.9 \%$ and $65.3 \%$, respectively, in group B patients ( $\mathrm{p}=0.0079$ ). In group A patients, ACEI/ARB or $\beta$ blockers were less frequently used $(\mathrm{p}<0.0001)$, whereas antiarrhythmics (class Ia or $\mathrm{Ib}$ ) were more often used $(\mathrm{p}<0.0001)$. The patients treated with ACEI/ARB and $\beta$ blockers showed a better survival rate than those without $(\mathrm{p}<0.0001)$. The patients with antiarrhythmics showed a worse survival rate than those without $(\mathrm{p}<0.0001)$.

Conclusion The prognosis of Japanese patients with DCM has significantly improved over the past 20 years. This improvement may be explained partly through the increased use of ACEI/ARB and $\beta$ blockers and a declining use of antiarrhythmics. (Circ J 2006; 70: 376-383)
\end{abstract}

Key Words: Dilated cardiomyopathy; Prognosis

I

diopathic dilated cardiomyopathy had a poor prognosis in the past ${ }^{1-5}$ Many randomized clinical trials performed in the United States of America and Europe have shown the beneficial effects of angiotensin converting enzyme inhibitors (ACEI) ${ }^{6-9}$ angiotensin II receptor blockers (ARB) $)^{10-13}$ and $\beta$ blockers on the survival of the patients with congestive heart failure! ${ }^{14-19}$ In contrast, only 2 small randomized studies of ARB (candesartan) ${ }^{20}$ and $\beta$ blocker (carvedilol) have been performed in Japan to date in patients with congestive heart failure ${ }^{21}$ There are no randomized studies of ACEI.

Although there are few reports concerning the long-term prognosis of Japanese patients with dilated cardiomyopathy (DCM) after ACEI, ARB and $\beta$ blockers became major components of background therapy in the management of all stages of patients with DCM, the beneficial effects of ACEI/ARB and $\beta$ blockers on the prognosis of Japanese patients with DCM have not clearly been shown in these studies ${ }^{2-28}$ Some studies even failed to reveal favorable effects of ACEI or $\beta$ blockers on the survival of Japanese patients with $\mathrm{DCM}_{2,27,28}$ It also remains uncertain whether antiarrhythmics ${ }^{23,29}$ or spironolactone have significant effects on the prognosis of Japanese patients with $\mathrm{DCM},{ }^{23}$

(Received October 19, 2005; revised manuscript received December 9, 2005; accepted January 11, 2006)

Department of Medicine and Geriatrics, Kochi Medical School, Kochi University, Kochi, Japan

Mailing address: Yoshinori Doi, MD, Department of Medicine and Geriatrics, Kochi Medical School, Kochi University, Oko-cho, Nankoku-shi, Kochi 783-8505, Japan. E-mail: ydoi@med.kochi-u. ac.jp though previous studies in Western countries have shown an adverse effect of antiarrhythmics ${ }^{30-34}$ and a favorable effect of spironolactone on the prognosis ${ }^{35}$

Thus, little information exists concerning changes in the prognosis of Japanese patients with DCM, to whom the recent trend in the survival should be informed, in relation to treatment.

The purpose of the presemt study was to analyze the changes in the long-term prognosis in Japanese patients with DCM over the past 20 years and to identify the factors that might have influenced survival.

\section{Methods}

Study Patients

We studied 150 patients (115 men and 35 women, aged 20-83 (mean $=59 \pm 11$ ) years) with idiopathic DCM who were referred to our hospital between 1982 and 2002. Ninety patients were in the New York Heart Association functional class I or II, and 60 patients were in class III or IV. A careful history was taken from all the patients, and they were given a physical examination, blood test, chest $\mathrm{X}$ ray, standard echocardiography, exercise stress test and cardiac catheterization, including coronary angiography and biplane left ventriculography. The diagnostic criteria were: (1) a dilated left ventricle (end-diastolic dimension (LVDd) $>55 \mathrm{~mm}$ ) with fractional shortening (LVFS) $<25 \%$; and (2) exclusion of patients with acute myocarditis, specific heart muscle disease, general systemic disease, significant coronary artery stenosis (defined as diameter narrowing of $>50 \%$ in any of the major coronary arteries or their 
Table 1 Baseline Clinical Characteristics and Medical Treatments

\begin{tabular}{|c|c|c|c|}
\hline & $\begin{array}{c}\text { Group A } \\
(1982-1989)\end{array}$ & $\begin{array}{c}\text { Group B } \\
(1990-2002)\end{array}$ & $p$ value \\
\hline Patients (n) & 46 & 104 & \\
\hline Age (years) & $58 \pm 11$ & $59 \pm 12$ & $N S$ \\
\hline $\operatorname{Sex}(M / F)$ & $33 / 13$ & $82 / 22$ & $N S$ \\
\hline NYHA class $(I-I I / I I I-I V)$ & $26 / 20$ & $64 / 40$ & $N S$ \\
\hline Atrial fibrillation (\%) & $8(17 \%)$ & $27(26 \%)$ & $N S$ \\
\hline Loop diuretics & $44(96 \%)$ & $89(86 \%)$ & $N S$ \\
\hline Digitalis & $37(80 \%)$ & $73(70 \%)$ & $N S$ \\
\hline$A C E I / A R B$ & $14(30 \%)$ & $95(91 \%)$ & $<0.0001$ \\
\hline$\beta$-blocker & $0(0 \%)$ & $55(53 \%)$ & $<0.0001$ \\
\hline $\begin{array}{l}\text { Antiarrhythmics } \\
\text { (class Ia/Ib) }\end{array}$ & $13 / 14(59 \%)$ & $1 / 9(10 \%)$ & $<0.0001$ \\
\hline Spironolactone & $34(74 \%)$ & $27(26 \%)$ & $<0.0001$ \\
\hline
\end{tabular}

NYHA, New York Heart Association; ACEI, angiotensin-converting enzyme inhibitors; ARB, angiotensin II receptor blockers.

branches), valvular disease, sensitivity/toxic reactions and a history of excessive alcohol intake. Coronary angiography was performed in 138 patients; none had significant coronary artery stenosis. Exercise electrocardiography and/or thallium-201 myocardial scintigraphy were negative for the remaining 12 patients who also showed no clinical or electrocardiographic (at rest) evidence of coronary artery disease. Atrial fibrillation was found in 35 patients.

Standard background therapy before 1990 consisted of diuretic agents, digoxin and some vasodilators. After 1990, there have been an increase in the use of ACEI and $\beta$ blockers, and a decrease in the use of antiarrhythmics (class Ia and $\mathrm{Ib}$ ) at our hospital. Therefore, we divided the patients into 2 groups according to their date of initial diagnosis: group A: 46 patients diagnosed between January 1982 and December 1989; group B: 104 patients diagnosed between January 1990 and December 2002.

\section{Follow-up}

End points for follow-up were death or heart transplantation. For the purpose of analysis, patients who died of cardiac causes (sudden death and heart failure death) or had a heart transplant were regarded as one group. The follow-up data were obtained by regular visits at our hospital, interviews with referring physicians and/or chart reviews, and by telephone contact with the patients or their relatives. The study closed on 31 August 2004.

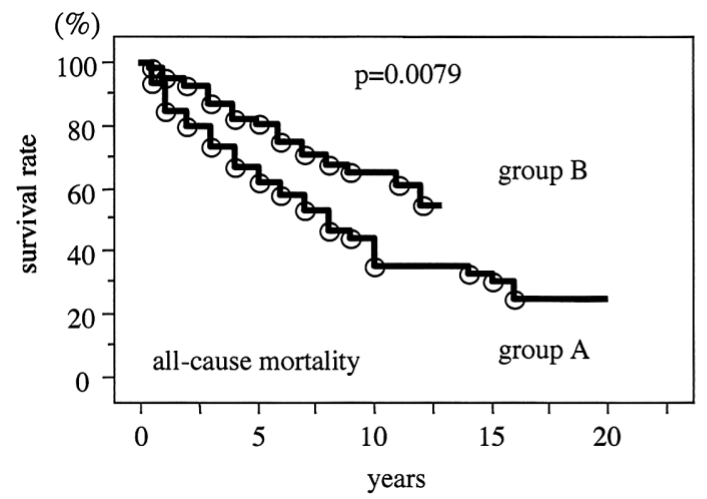

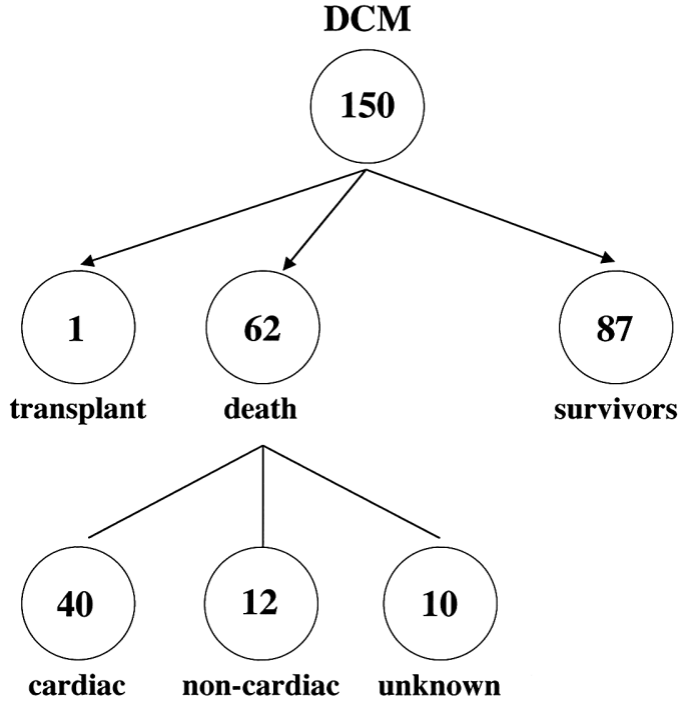

Fig 1. Clinical outcomes during follow-up periods. DCM, dilated cardiomyopathy.

\section{Statistical Analysis}

The results were expressed as mean \pm SD. A chi-square test was used to compare categorical variables. Group data were compared using the unpaired Student's t-test. Survival estimates were obtained using the Kaplan-Meier method.

The severity of left ventricular (LV) systolic dysfunction, determined by echocardiogram, was used to stratify the survival curves of the patients in groups A and B. The patients in each group were divided into 2 strata-those with LVFS $>15 \%$ and those with LVFS $\leq 15 \%$ - as the mean value of LVFS was $15 \%$ in all the patients.

The multivariate Cox proportional hazards model was used to analyze the relationship between survival and prognostic indices. A p value $<0.05$ was considered statistically significant.

\section{Results}

\section{Baseline Characteristics}

The baseline clinical characteristics of the patients in groups A and B are shown in Table 1. There were no differences in clinical findings except medical treatment. In the group $\mathrm{A}, \mathrm{ACEI} / \mathrm{ARB}$ or $\beta$ blockers were less frequently

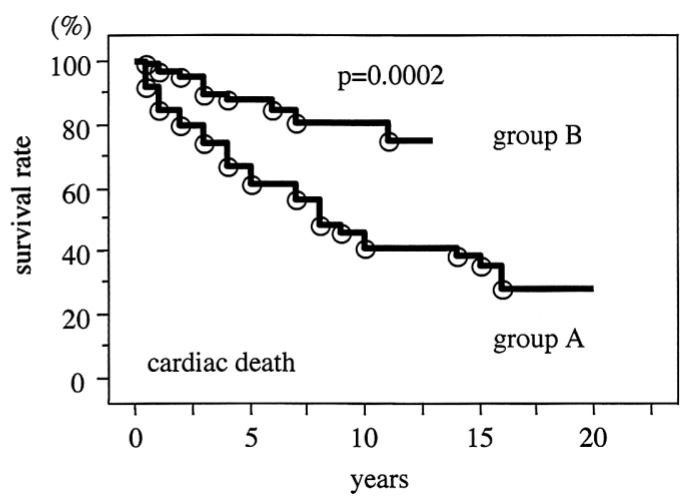

Fig 2. Kaplan-Meier curves for all-cause mortality (Left) (group A ( $=46)$ and group B $(n=104)$ ) and cardiac death (Right) (group A $(n=39)$ and group B $(n=89)$ ) of the patients. 
Table 2 Echocardiographic and Cardiac Catheterization Findings

\begin{tabular}{|c|c|c|c|}
\hline & $\begin{array}{c}\text { Group A } \\
(1982-1989)\end{array}$ & $\begin{array}{c}\text { Group B } \\
(1990-2002)\end{array}$ & $p$ value \\
\hline $\operatorname{LVDd}(\mathrm{mm})$ & $65 \pm 6$ & $63 \pm 7$ & 0.0351 \\
\hline $\operatorname{LVDs}(\mathrm{mm})$ & $56 \pm 7$ & $53 \pm 8$ & 0.0238 \\
\hline $\operatorname{LVFS}(\%)$ & $14 \pm 5$ & $16 \pm 6$ & $N S$ \\
\hline $\operatorname{IVS}(\mathrm{mm})$ & $10 \pm 2$ & $10 \pm 2$ & $N S$ \\
\hline$L V P W(\mathrm{~mm})$ & $10 \pm 2$ & $10 \pm 2$ & $N S$ \\
\hline$L A(m m)$ & $41 \pm 7$ & $42 \pm 7$ & $N S$ \\
\hline $\operatorname{LVEDVI}\left(\mathrm{ml} / \mathrm{m}^{2}\right)$ & $146 \pm 43$ & $147 \pm 45$ & $N S$ \\
\hline $\operatorname{LVESVI}\left(\mathrm{ml} / \mathrm{m}^{2}\right)$ & $99 \pm 38$ & $99 \pm 41$ & $N S$ \\
\hline $\operatorname{LVEF}(\%)$ & $32 \pm 11$ & $34 \pm 9$ & $N S$ \\
\hline LVEDP $(\mathrm{mmHg})$ & $15 \pm 7$ & $12 \pm 7$ & 0.0337 \\
\hline$P C W P(m m H g)$ & $11 \pm 6$ & $10 \pm 7$ & $N S$ \\
\hline$P A$, mean $(m m H g)$ & $21 \pm 10$ & $19 \pm 8$ & $N S$ \\
\hline RVEDP (mmHg) & $8 \pm 3$ & $7 \pm 3$ & $N S$ \\
\hline$R A$, mean $(\mathrm{mmHg})$ & $6 \pm 4$ & $6 \pm 4$ & $N S$ \\
\hline Ao, systolic $(\mathrm{mmHg})$ & $119 \pm 22$ & $117 \pm 22$ & $N S$ \\
\hline $\begin{array}{l}\text { Cardiac index } \\
\left(\mathrm{ml} \cdot \mathrm{min}^{-1} \cdot \mathrm{m}^{-2}\right)\end{array}$ & $2.3 \pm 0.6$ & $2.2 \pm 0.6$ & $N S$ \\
\hline
\end{tabular}

$L V$, left ventricle; $D d$, end-diastolic dimension; $D$ s, end-systolic dimension; $F S$, fractional shortening; IVS, interventricular septum; $P W$, posterior wall; LA, left atrium; EDVI, end-diastolic volume index; ESVI, end-systolic volume index; EF, ejection fraction; EDP, end-diastolic pressure; PCWP, pulmonary capillary wedge pressure; $P A$, pulmonary artery; $R V$, right ventricle; RA, right atrium; Ao, aorta.

used than in group B $(\mathrm{p}<0.0001)$, whereas antiarrhythmics (class Ia or Ib) were more often used $(\mathrm{p}<0.0001)$. Also, in group A, spironolactone were more often used than in group $\mathrm{B}(\mathrm{p}<0.0001)$. ACEI were administered in 100 patients, and ARB administered in 9 patients. Enalapril (2.5-10 (mean $5.3 \pm 1.7) \mathrm{mg}$ daily) and captopril (25-37.5 (mean 31.0 \pm 8.4 ) $\mathrm{mg}$ daily) were the most frequently used ACEI (74\%). Losartan (25-50 (mean 30.0 \pm 11.1$)$ mg daily) was the most frequently used ARB (56\%). Beta blockers were administered in 55 patients: carvedilol (2.5-20 (mean 9.5 \pm 4.9$) \mathrm{mg}$ daily) in 30 patients and metoprolol (20-120 (mean 61.6 30.6) $\mathrm{mg}$ daily) in 25 patients.

The baseline echocardiographic and cardiac catheterization data of the patients in groups A and B are shown in Table 2. There were no differences in echocardiographic findings except LVDd and LV end-systolic dimension. There were no differences in hemodynamic findings except LV end-diastolic pressure (LVEDP).

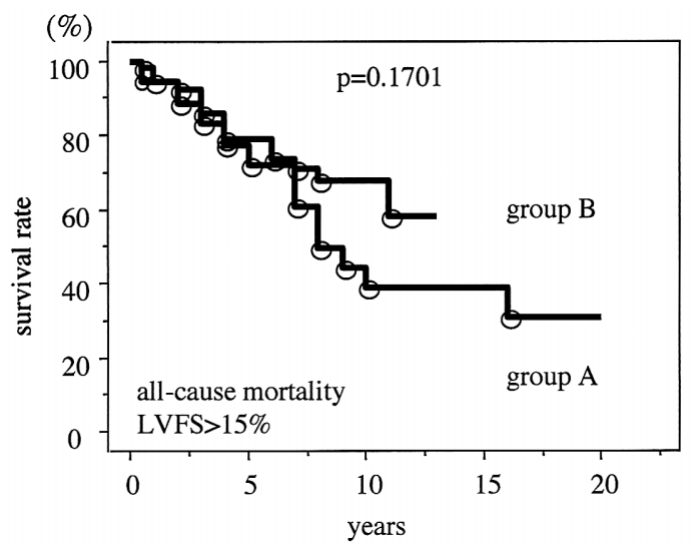

Table 3 Long-Term Prognosis

\begin{tabular}{|c|c|c|c|}
\hline & $\begin{array}{c}\text { Group A } \\
(1982-1989)\end{array}$ & $\begin{array}{c}\text { Group B } \\
(1990-2002)\end{array}$ & $p$ value \\
\hline Follow-up periods (years) & $8.8 \pm 6.1$ & $6.2 \pm 3.8$ & 0.0038 \\
\hline All-cause mortality & $34(74 \%)$ & $29(27 \%)$ & $<0.0001$ \\
\hline Cardiac death & $27(59 \%)$ & $14(13 \%)$ & $<0.0001$ \\
\hline $\begin{array}{l}\text { 5-year survival rate (\%) } \\
\text { (all-cause mortality) }\end{array}$ & 60.9 & 80.9 & 0.0079 \\
\hline $\begin{array}{l}\text { 10-year survival rate (\%) } \\
\text { (all-cause mortality) }\end{array}$ & 34.8 & 65.3 & 0.0079 \\
\hline $\begin{array}{l}\text { 5-year survival rate }(\%) \\
\text { (cardiac death) }\end{array}$ & 61.5 & 88.2 & 0.0002 \\
\hline $\begin{array}{l}\text { 10-year survival rate }(\%) \\
\text { (cardiac death) }\end{array}$ & 43.6 & 81.0 & 0.0002 \\
\hline
\end{tabular}

\section{Long-Term Prognosis (All-Cause Mortality and Cardiac Death)}

During the follow-up period of $6.9 \pm 4.8$ years, 62 patients died (40 cardiac, 12 non-cardiac and 10 unknown causes), 1 patient had a heart transplant and 87 patients survived (Fig 1). Of the 41 patients who died of cardiac cause or had a heart transplant, 27 were in the group A and 14 in the group B.

Kaplan-Meier analysis showed that survival curves for all-cause mortality and cardiac death were significantly worse in group A than in group B, respectively (Fig 2). The calculated survival rate for all-cause mortality at 5 and 10 years was $60.9 \%$ and $34.8 \%$, respectively, in group A, and $80.9 \%$ and $65.3 \%$, respectively, in group $\mathrm{B}(\mathrm{p}=0.0079)$ (Table 3). The calculated survival rate for cardiac death at 5 and 10 years was $61.5 \%$ and $43.6 \%$, respectively, in group $\mathrm{A}$, and $88.2 \%$ and $81.0 \%$, respectively, in group B ( $\mathrm{p}=$ 0.0002) (Table 3).

After stratification according to the severity of LV systolic dysfunction, the survival curves for cardiac death in the groups A and B were significantly different in 73 patients with LVFS $>15 \%$, though those for all-cause mortality were not (Fig 3). The survival curves for all-cause mortality and cardiac death in the groups A and B were also significantly different in 77 patients with LVFS $\leq 15 \%$ (Fig 4).

\section{Cardiac Death and Medical Treatment}

The incidence of cardiac death was significantly lower in patients treated with ACEI/ARB than in those without $(\mathrm{p}<$

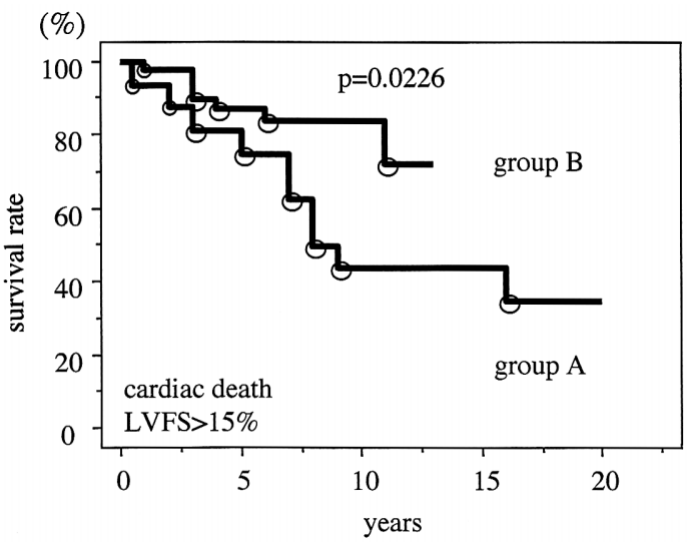

Fig 3. Kaplan-Meier curves for all-cause mortality (Left) (group A ( $=18)$ and group B $(n=55)$ ) and cardiac death (Right) (group A $(n=16)$ and group B $(n=46)$ ) of the patients with LVFS $>15 \%$. LVFS, left ventricular fractional shortening. 

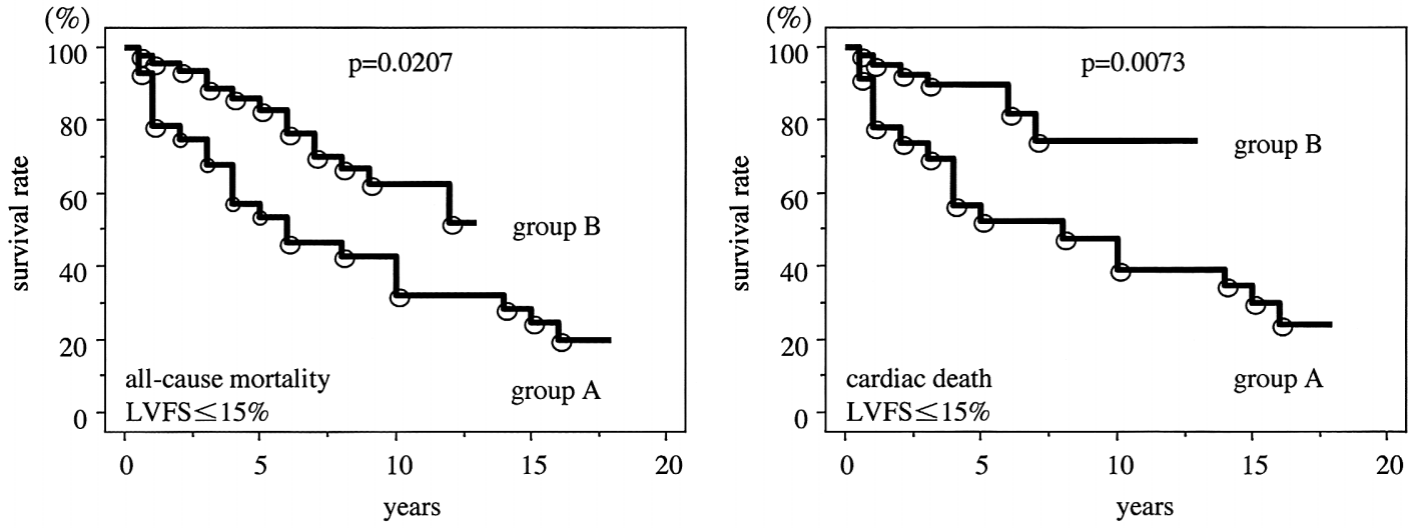

Fig 4. Kaplan-Meier curves for all-cause mortality (Left) (group A ( $=28)$ and group $B(n=49)$ ) and cardiac death (Right) (group A $(n=23)$ and group B $(n=43))$ of the patients with LVFS $\leq 15 \%$. LVFS, left ventricular fractional shortening.

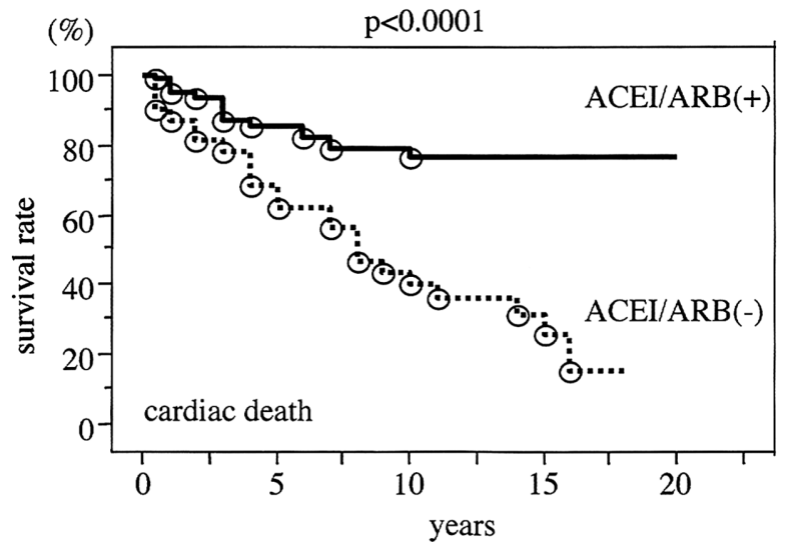

Fig 5. Survival curves of the patients treated with and without ACEI/ARB (ACEI/ARB $(+)(n=96)$ and ACEI/ARB $(-)(n=32))$. ACEI, angiotensin converting enzyme inhibitors; ARB, angiotensin II receptor blockers.

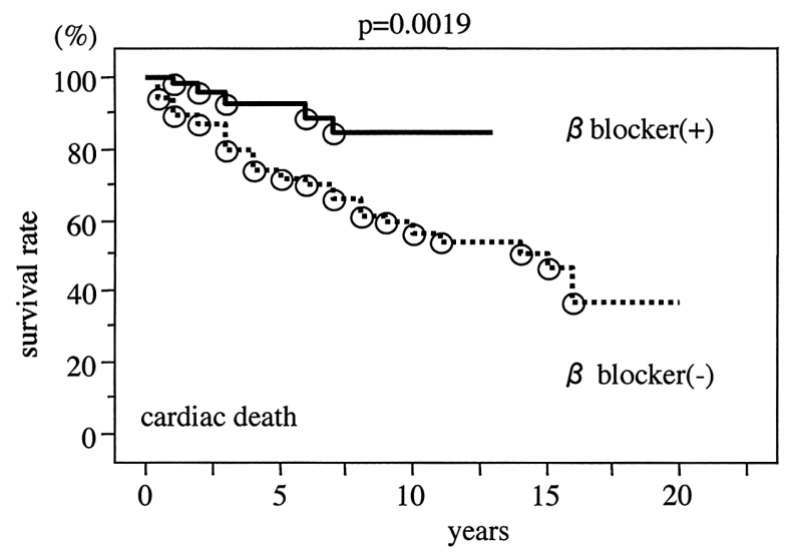

Fig 6. Survival curves of the patients treated with and without $\beta$ blockers $(\beta$ blocker $(+)(n=55)$ and $\beta$ blocker $(-)(n=73))$.

0.0001) (Fig 5). It was also significantly lower in patients treated with $\beta$ blockers than in those without $(\mathrm{p}=0.0019)$ (Fig 6).

The patients treated with ACEI/ARB and $\beta$ blockers showed a better survival than those with ACEI/ARB only

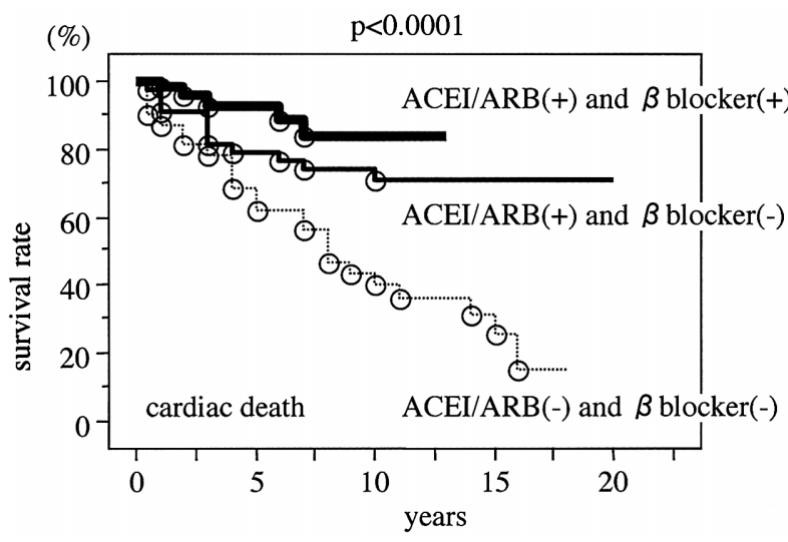

Fig 7. Survival curves of the patients treated with and without ACEI/ARB and $\beta$ blockers (ACEI/ARB $(+)$ and $\beta$ blocker $(+)(n=54)$, ACEI/ARB $(+)$ and $\beta$ blocker $(-)(n=42)$, and ACEI/ARB $(-)$ and $\beta$ blocker $(-)(n=32))$. ACEI, angiotensin converting enzyme inhibitors; $\mathrm{ARB}$, angiotensin II receptor blockers.

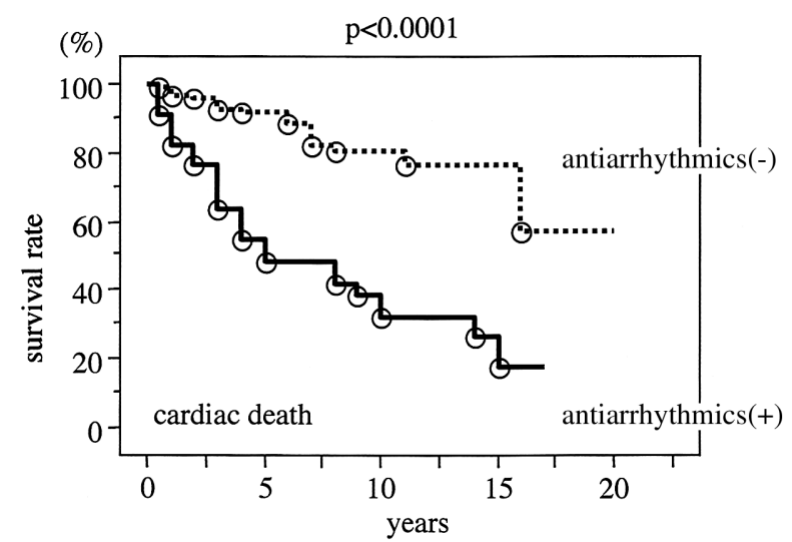

Fig 8. Survival curves of the patients treated with and without antiarrhythmics (antiarrhythmics $(+)(\mathrm{n}=37)$ and antiarrhythmics $(-)$ $(n=91))$.

and those without $(\mathrm{p}<0.0001)$ (Fig 7).

The incidence of cardiac death was significantly higher in patients treated with antiarrhythmics than in those without $(\mathrm{p}<0.0001)$ (Fig 8). There was no significant difference in the incidence of cardiac death between patients with class 
Table 4 Predictors of Cardiac Death (Multivariate Cox Proportional Hazard Analysis)

\begin{tabular}{lcr}
\hline \hline & Hazard ratio $(95 \%$ CI) & p value \\
\hline LVDd & $0.98(0.85-1.13)$ & 0.7725 \\
LVDs & $0.99(0.88-1.12)$ & 0.9157 \\
LVEDP & $1.11(1.05-1.16)$ & $<0.0001$ \\
ACEI/ARB + -blocker & $3.99(1.24-12.76)$ & 0.0199 \\
ACEI/ARB & $2.04(0.95-4.42)$ & 0.0689 \\
Antiarrhythmics & $0.37(0.15-0.92)$ & 0.0332 \\
Spironolactone & $0.93(0.37-2.37)$ & 0.8799 \\
\hline
\end{tabular}

$C I$, confidence interval; $L V$, left ventricle; $D d$, end-diastolic dimension; $D$ s, end-systolic dimension; EDP, end-diastolic pressure; ACEI, angiotensinconverting enzyme inhibitors; ARB, angiotensin II receptor blockers.

Ia antiarrhythmics and those with Ib antiarrhythmics.

The incidence of cardiac death was higher in patients treated with spironolactone than in those without. There was no difference in the incidence of cardiac death between patients treated with digitalis or loop diuretics and those without.

\section{Predictors of Cardiac Death}

The multivariate Cox proportional hazard analysis showed that the independent determinants of cardiac death were high LVEDP, the disuse of ACEI or ARB and $\beta$ blockers, and the use of antiarrhythmics (Table 4). Spironolactone was not a significant determinant of cardiac death.

\section{Discussion}

The present study demonstrates that the long-term prognosis of Japanese patients with DCM has significantly improved over the past 20 years. This improvement may partly be explained by an increased use of ACEI/ARB and $\beta$ blockers, and a declined use of antiarrhythmics.

\section{Improvement in the Survival in Patients With DCM Over the Past 20 Years}

The prognosis of patients with DCM was very poor in the past! ${ }^{-5}$ The median survival period was about 2 years after diagnosis, 1 and the survival rate at 5 years was about $50 \%$ ?

After a number of large randomized trials performed in the United States of America and Europe that suggest beneficial effects due to the use of ACEI/ARB and $\beta$ blockers on the survival of patients with LV systolic dysfunction, these drugs have become major components of background therapy in the management of all stages of patients with DCM-19

In Japan, however, only 2 small randomized studies of ARB (candesartan) ${ }^{20}$ and $\beta$ blocker (carvedilol) have been performed in patients with congestive heart failure ${ }^{21}$ There are no randomized studies of the effects of using ACEI. Although previous studies in Japan have reported an improvement in the survival of patients with DCM, these studies included limitations such as a small number of patients, relatively short follow-up periods and end point of all-cause mortality (not cardiac death) ${ }^{22-28}$ Therefore, it is unresolved whether the long-term prognosis of Japanese patients with DCM has improved because of improved treatments.

In the present study, survival rates for all-cause mortality and cardiac death were significantly lower in group A than in group B, respectively (Fig 2).
After stratification according to the severity of LV systolic dysfunction, this improvement in the survival was more evident in patients with LVFS $\leq 15 \%$ (Fig 4).

The survival curves for cardiac death in groups A and B were also significantly different in patients with LVFS $>15 \%$, though those for all-cause mortality were not (Fig 3). This discrepancy may probably be associated with the fact that the patients more frequently died of non-cardiac and unknown causes in group B than in group A.

The survival rate at 5 years was $60.9 \%$ for all-cause mortality in group A (diagnosis: 1982-1989) (Table 3). This survival rate was similar to that in the previous reports. However, in group B (diagnosis: 1990-2002), the survival rate at 5 years was $80.9 \%$ for all-cause mortality. Also, the survival rate for cardiac death at 5 and 10 years was $61.5 \%$ and $43.6 \%$ in group A and $88.2 \%$ and $81.0 \%$ in the group B. These results suggest the long-term prognosis of Japanese patients with DCM has significantly improved over the past 20 years.

\section{Factors Contributing to the Improvement in the Survival}

The patients in group A had slightly larger LV sizes and higher LVEDP than those in group $\mathrm{B}$, though other variables from echocardiography and cardiac catheterization were similar (Table2). It is possible that the patients in group A had more advanced myocardial changes at diagnosis than those in group B. We also found an increase in the number of patients in group B compared to that in group A. Relatively earlier diagnosis might have been made in those in group B, though the age at diagnosis was similar between groups $\mathrm{A}$ and $\mathrm{B}$.

ACEI and $\beta$ blockers were less frequently used in group A than in group B, whereas antiarrhythmics were more often used in group A (Table 1). The patients treated with ACEI/ARB or $\beta$ blockers showed a better survival than those without (Figs 5 and 6). Moreover, the patients treated both with ACEI/ARB and $\beta$ blockers showed a better survival than those treated with ACEI/ARB only and those without (Fig 7). The patients treatd with antiarrhythmics showed a worse survival than those without (Fig 8). These results indicate that an improvement in the long-term survival of patients with DCM can, at least in part, be explained by the advances in the pharmacologic treatment.

\section{The Use of ACEI/ARB or $\beta$ Blockers}

$A C E I / A R B$ Although ACEI and ARB have been believed to have favorable prognostic effects, the use of ACEI ${ }^{23,27,28}$ and ARB has not been shown to have favorable effects on the prognosis of Japanese patients with congestive heart failure 20 Azuma et al reported that the use of ACEI did not significantly affect long-term survival in patients with DCM? ${ }^{23}$ In the CHART study, the use of ACEI also did not improve the prognosis in Japanese patients with nonischemic cardiomyopathy ${ }^{27,28}$ Despite these negative data in Japanese patients with DCM, the present study provided clear evidence that the use of ACEI/ARB had favorable effects on prognosis (Fig 5).

Beta Blockers There is little evidence that the use of $\beta$ blockers has favorable effects on prognosis of Japanese patients with chronic heart failure. The MUCHA trial demonstrated that carvedilol therapy achieved improvement in the combined end point, which was all-cause mortality or cardiovascular hospitalization, in Japanese patients with chronic heart failure ${ }^{11}$ However, it could not be fully determined whether carvedilol lowers the cardiac death in 
patients with chronic heart failure. Although the beneficial effects of $\beta$ blockers on the prognosis of Japanese patients with DCM have been shown in the previous retrospective studies 23,26 the CHART study failed to reveal favorable effects from $\beta$ blockers on prognosis of Japanese patients with nonischemic cardiomyopathy 27,28

In the present study, $\beta$ blockers had favorable effects on the prognosis of Japanese patients with DCM (Fig 6). Moreover, the addition of $\beta$ blockers was more beneficial to patients with DCM who had been treated with ACEI/ARB (Fig 7). The Cox proportional hazard analysis also showed the disuse of ACEI/ARB and $\beta$ blockers as the independent determinants of cardiac deaths (Table 4 ).

\section{The Doses of ACEI/ARB or $\beta$ Blockers}

$A C E I / A R B$ The targeting doses of ACEI or ARB are much higher in previous randomized clinical trials performed in the Unites States of America and Europe than those used in clinical practice in Japan6-13 For example, in the CONSENSUS study, the target dose of ACEI (enalapril) was $40 \mathrm{mg}$ daily? In the ELITE II trial, the dose of ACEI (captopril) was $150 \mathrm{mg}$ daily, and that of ARB (losartan) was $50 \mathrm{mg}$ daily!1

It is still controversial whether low doses and high doses of ACEI have similar beneficial effects on prognosis in chronic heart failure. For example, Packer et al have reported that the use of high doses (32.5-35 $\mathrm{mg}$ daily) instead of low doses (2.5-5.0 mg daily) of ACEI (lisinopril) reduces the risk of major clinical events in patients with chronic heart failure 36 In contrast, in other studies, high doses (20 mg daily) of ACEI (enalapril) were not superior to low doses ( $5 \mathrm{mg}$ daily) 37 In the present study, the low dose of ACEI/ARB was effective in reducing the risk of cardiac death in Japanese patients with DCM (Fig 5).

Beta Blockers The target doses of $\beta$ blockers are also much higher in previous randomized clinical trials performed in the Unites States of America and Europe than those used for the treatment of congestive heart failure in Japan!4-19 In the MERIT-HF study, the target dose of metoprolol was $200 \mathrm{mg}$ daily ${ }^{17}$ In the US MOCHA trial, the target dose of carvedilol was $50 \mathrm{mg}$ daily 15

In Western countries, the recommended dose of carvedilol is $50 \mathrm{mg}$ daily for maintenance treatment of congestive heart failure! 153 In Japan, in the MUCHA trial, low dose carvedilol (5-20 mg daily) reduced the risk of allcause mortality or cardiovascular hospitalization.1 The difference in the effective dose between patients in Japan and those in Western countries may depend on different drug absorption and metabolism, different $\beta 1$ receptor sensitivity and different body size 39,40 The MUCHA trial suggested that the recommended dose of carvedilol for Japanese patients with congestive heart failure should range from 5 to $20 \mathrm{mg}$ daily. In the present study, the low dose $\beta$ blockers also achieved a marked reduction in the risk of cardiac death (Fig 6).

These results indicated that even the low dose regimens of ACEI/ARB or $\beta$ blockers have favorable effects on prognosis of Japanese patients with DCM.

\section{The Use of Antiarrhythmics}

The studies performed in Western countries have shown adverse effects from antiarrhythmics (class I) on the survival of patients with congestive heart failure, probably because of negative inotropic effects and proarrhythmia.30-34 However, previous studies in Japan have not shown adverse effects of antiarrhythmics on the prognosis of patients with DCM 23,29 In the present study, the patients treated with antiarrhythmics (class Ia or Ib) showed a worse survival rate than those without (Fig 8). There was no significant difference in the incidence of cardiac death between patients treated with class Ia antiarrhythmics and those with Ib. There was no patient treated with amiodarone in this study.

The reasons for the use of antiarrhythmics were unclear because Holter electrocardiographic findings were not available for all the study patients. It may be possible that the presence of atrial and/or ventricular arrhythmias was associated with poor prognosis in patients with antiarrhythmics, though the incidence of atrial fibrillation at diagnosis was similar between the patients with antiarrhythmics and those without. Another possibility is the change of strategies for the use of arrhythmias.

Class Ia or Ib antiarrhythmics should be used with caution in the management of patients with DCM41 Also, class Ic antiarrhythmics should not be used in patients with LV systolic dysfunction because of its negative inotropic effect and proarrhythmia. The Sicilian Gambit meetings suggested that the "upstream" approach to antiarrhythmic therapy should be considered first in patients with DCM who have arrhythmias. ${ }^{2}$ Environmental factors associated with arrhythmia, including pathogenic factors, hemodynamic load, myocardial perfusion and others, should be modified before the use of antiarrhythmics. The use of ACEI/ARB and $\beta$ blockers is one of the "upstream" approaches to arrhythmias because of their effectiveness in preventing LV remodeling and improving LV systolic function. These changes of strategies for the arrhythmias might also be associated with the declined use of antiarrhythmics in the group B.

\section{The Use of Spironolactone and Other Drugs}

Spironolactone, digitalis and loop diuretics did not significantly affect long-term survival in this study, though a recent report has shown the favorable effect of spironolactone on the survival of patients with severe congestive heart failure 35 At first, the patients treated with spironolactone appeared to show a worse survival rate than those without in this study. However, spironolactone did not significantly affect long-term survival when the patients with antiarrhythmics were excluded from the analysis. The Cox proportional hazard analysis also did not show spironolactone as a significant determinant of cardiac death.

\section{Predictors of Cardiac Death}

The Cox proportional hazard analysis revealed that high LVEDP, the disuse of ACEI and $\beta$ blockers, and the use of antiarrhythmics (class Ia or Ib) were the significant predictors of cardiac death (Table4). These results suggest that the patients with high LVEDP, who probably have more advanced myocardial changes, show worse prognoses. The use of both ACEI and $\beta$ blockers, and the disuse of antiarrhythmics (class Ia or Ib) could significantly improve the long-term survival of Japanese patients with DCM.

\section{Clinical Implications}

This awareness of the improvement in the survival rate of Japanese patients with DCM will help us provide up-todate treatment information for the majority of patients with DCM. Both ACEI/ARB and $\beta$ blockers should be strongly recommended as background therapy, whereas antiarrhyth- 
mics (class Ia or Ib) should be used with caution in the management of patients with DCM.

\section{Limitations}

The present study was not prospective and randomized. The number of the subjects was small so some of the statistical analyses might have been affected. The improvement in the survival rate of the patients with DCM might be related to other factors such as earlier diagnosis, differences in the clinical characteristics of the patients at diagnosis and referral bias. There was an increase in the number of patients in group B. Relatively earlier diagnoses might have been made in those in group B, though the age at diagnosis was similar between groups $\mathrm{A}$ and $\mathrm{B}$. The LVDd and LVDs were slightly larger, and LVEDP was also higher in group A than in group B. It is possible that the patients in group A had poorer prognoses than those in group B due to the advanced stage of their disease. However, the survival curves for cardiac death in groups A and $B$ were still significantly different after stratification according to the severity of LV systolic dysfunction. Also, the reasons for the use of antiarrhythmics were unclear. It may be possible that the presence of atrial and/or ventricular arrhythmias was associated with poor prognosis in patients with antiarrhythmics, though the incidence of atrial fibrillation at diagnosis was similar between the patients treated with antiarrhythmics and those without.

The results of medical treatment were analyzed on an intention to treat basis (prescribed at diagnosis). Recent non-medical therapies (such as implantable cardioverter defibrillators, bi-ventricular pacing, mitral valve surgery and LV volume reduction) could affect the prognosis in patients with DCM, though no patients were treated with these therapies in the present study. Further studies with a large number of Japanese patients with long-term followup are required.

\section{References}

1. Fuster V, Gersh BJ, Giuliani ER, Tajik AJ, Brandenburg RO, Frye RL. The natural history of idiopathic dilated cardiomyopathy. Am J Cardiol 1981; 47: 525-531.

2. Kawai C, Sakurai T, Kishimoto C, Tomioka N. A follow-up survey for the prognosis of idiopathic cardiomyopathies in Japan. In: Research Committee on Idiopathic Cardiomyopathy. Annual Report. Tokyo: Ministry of Health and Welfare; 1983; 63-66 (in Japanese).

3. Ogasawara S, Sekiguchi M, Hiroe M, Komazawa T, Kawai Y, Fujita N, et al. Prognosis of dilated cardiomyopathy: From a retrospective to a prospective study employing multivariate analysis. Jpn Circ J 1987; 51: 699-706.

4. Diaz RA, Obasohan A, Oakley CM. Prediction of outcome in dilated cardiomyopathy. Br Heart J 1987; 58: 393-399.

5. Doi YL, Chikamori T, Takata J, Yonezawa Y, Poloniecki JD, Ozawa T, et al. Prognostic value of thallium-201 perfusion defects in idiopathic dilated cardiomyopathy. Am J Cardiol 1991; 67: 188-193.

6. The CONSENSUS Trial Study Group. Effects of enalapril on mortality in severe congestive heart failure: Results of the Cooperative North Scandinavian Enalapril Survival Study (CONSENSUS). $N$ Engl J Med 1987; 316: 1429-1435.

7. The SOLVD Investigators. Effect of enalapril on survival in patients with reduced left ventricular ejection fractions and congestive heart failure. N Engl J Med 1991; 325: 293-302.

8. Cohn JN, Johnson G, Ziesche S, Cobb F, Francis G, Tristani F, et al. A comparison of enalapril with hydralazine-isosorbide dinitrate in the treatment of chronic congestive heart failure. N Engl J Med 1991; 325: $303-310$.

9. The SOLVD Investigators. Effect of enalapril on mortality and the development of heart failure in asymptomatic patients with reduced left ventricular ejection fractions. N Engl J Med 1992; 327: 685691.

10. Pitt B, Segal R, Martinez FA, Meurers G, Cowley AJ, Thomas I, et al.
Randomised trial of losartan versus captopril in patients over 65 with heart failure (Evaluation of Losartan in the Elderly Study, ELITE). Lancet 1997; 349: 747-752.

11. Pitt B, Poole-Wilson PA, Segal R, Martinez FA, Dickstein K, Camm AJ, et al. Effect of losartan compared with captopril on mortality in patients with symptomatic heart failure: Randomised trial-the Losartan Heart Failure Survival Study-ELITE II. Lancet 2000; 355: $1582-1587$.

12. Cohn JN, Tognoni G; Valsartan Heart Failure Trial Investigators. A randomized trial of the angiotensin-receptor blocker valsartan in chronic heart failure. $N$ Engl J Med 2001; 345: 1667-1675.

13. Granger CB, McMurray JJ, Yusuf S, Held P, Michelson EL, Olofsson $\mathrm{B}$ et al, CHARM Investigators and Committees. Effects of candesartan in patients with chronic heart failure and reduced left-ventricular systolic function intolerant to angiotensin-converting-enzyme inhibitors: The CHARM-Alternative trial. Lancet 2003; 362: 772-776.

14. Packer M, Bristow MR, Cohn JN, Colucci WS, Fowler MB, Gilbert EM, et al, US Carvedilol Heart Failure Study Group. The effect of carvedilol on morbidity and mortality in patients with chronic heart failure. N Engl J Med 1996; 334: 1349-1355.

15. Bristow MR, Gilbert EM, Abraham WT, Adams KF, Fowler MB, Hershberger RE, et al, MOCHA Investigators. Carvedilol produces dose-related improvements in left ventricular function and survival in subjects with chronic heart failure. Circulation 1996; 94: 2807 2816.

16. CIBIS-II investigators. The Cardiac Insufficiency Bisoprolol Study II (CIBIS-II): A randomized trial. Lancet 1999; 353: 9-13.

17. Metoprolol CR/XL Randomised Intervention Trial in Congestive Heart Failure (MERIT-HF) Study Group. Effect of metoprolol CR/XL in chronic heart failure. Lancet 1999; 353: 2001-2007.

18. The Beta-Blocker Evaluation of Survival Trial investigators. A trial of the beta-blocker bucindolol in patients with advanced chronic heart failure. N Engl J Med 2001; 44: 1659-1667.

19. Packer M, Fowler MB, Roecker EB, Coats AJS, Katus HA, Krum H, et al. Effect of carvedilol on the morbidity of patients with severe chronic heart failure: Results of the carvedilol prospective randomized cumulative survival (COPERNICUS) study. Circulation 2002; 106: $2194-2199$.

20. Matsumori A, on behalf of the Assessment of Response to Candesartan in Heart Failure in Japan (ARCH-J) Study Investigators. Efficacy and safety of oral candesartan cilexetil in patients with congestive heart failure. Eur J Heart Fail 2003; 5: 669-677.

21. Hori M, Sasayama S, Kitabatake A, Toyo-oka T, Handa S, Yokoyama $\mathrm{M}$, et al, MUCHA Investigators. Low-dose carvedilol improves left ventricular function and reduces cardiovascular hospitalization in Japanese patients with chronic heart failure: The Multicenter Carvedilol Heart Failure Dose Assessment (MUCHA) trial. Am Heart J 2004; 147: $324-330$

22. Yokota Y, Tsumura Y, Takarada A, Kawai H, Yokoyama M. The effect of recent advances in pharmacologic management on the prognosis of dilated cardiomyopathy. Jpn Circ J 1993; 57: 1038-1046.

23. Azuma A, Matsuo A, Nakamura T, Kawasaki T, Yamamoto K, Hyogo M, et al. Improved survival of idiopathic dilated cardiomyopathy in the 1990s. Jpn Circ J 1999; 63: 333-338.

24. Matsumori A, Furukawa Y, Hasegawa K, Sato Y, Nakagawa H, Morikawa Y, et al. Epidemiologic and clinical characteristics of cardiomyopathies in Japan: Results from nationwide surveys. Circ $J$ 2002; 66: $323-336$.

25. Yabe T, Furuno T, Kitaoka H, Matsumura Y, Yamasaki N, Doi Y. Thallium scintigraphy for the prognosis of idiopathic dilated cardiomyopathy. J Cardiol 2002; 40: 207-215.

26. Hamada M, Hara Y, Ohtsuka T, Suzuki J, Saeki H, Ogimoto A, et al. Effect of the addition of a beta-blocker on left ventricular remodeling and prognosis in patients with dilated cardiomyopathy treated with angiotensin-converting enzyme inhibitor. J Cardiovasc Pharmacol 2003; 41: S5-S10

27. Shiba N, Watanabe J, Shinozaki T, Koseki Y, Sakuma M, Kagaya Y, et al, CHART Investigators. Analysis of chronic heart failure registry in the Tohoku district: Third year follow-up. Circ J 2004; 68: $427-$ 434.

28. Shiba N, Watanabe J, Shinozaki T, Koseki Y, Sakuma M, Kagaya Y, et al. Poor prognosis of Japanese patients with chronic heart failure following myocardial infarction: Comparison with nonischemic cardiomyopathy. Circ J 2005; 69: 143-149.

29. Takarada A, Yokota Y, Fukuzaki H. Analysis of ventricular arrhythmias in patients with dilated cardiomyopathy: Relationship between the effects of antiarrhythmic agents and severity of myocardial lesions. Jpn Circ J 1990; 54: 260-271.

30. The Cardiac Arrhythmia Suppression Trial (CAST) Investigators. Preliminary report: Effect of encainide and flecainide on mortality in 
a randomized trial of arrhythmia suppression after myocardial infarction. N Engl J Med 1989; 321: 406-412.

31. Epstein AE, Bigger JT, Wyse DG, Romhilt DW, Reynolds-Haertle RA, Hallstrom AP and the CAST investigators. Events in the Cardiac Arrhythmia Suppression Trial (CAST): Mortality in the entire population enrolled. J Am Coll Cardiol 1991; 18: 14-19.

32. Yusuf S, Teo KK. Approaches and prevention of sudden death: Need for fundamental reevaluation. J Cardiovasc Electrophysiol 1991; 2: $5233-5239$

33. The Cardiac Arrhythmia Suppression Trial investigators. Effect of the antiarrhythmic agent moricizine on survival after myocardial infarction. N Engl J Med 1992; 327: 227-233.

34. Flaker GC, Blackshear JL, McBride R, Kronmal RA, Halperin JL, Hart RG, The Stroke Prevention in Atrial Fibrillation Investigators. Antiarrhythmic drug therapy and cardiac mortality in atrial fibrillation. J Am Coll Cardiol 1992; 20: 527-532.

35. Pitt B, Zannad F, Remme WJ, Cody R, Castaigne A, Perez A, et al. The effect of spironolactone on morbidity and mortality in patients with severe heart failure. N Engl J Med 1999; 341: 709-717.

36. Packer M, Poole-Wilson PA, Armstrong PW, Cleland JGF, Horowitz JD, Massie BM, et al, on behalf of the ATRAS study group. Comparative effects of low and high doses of the angiotensin-converting enzyme inhibitor, lisinopril, on morbidity and mortality in chronic heart failure. Circulation 1999; 100: 2312-2318.

37. The NETWORK Investigators. Clinical outcome with enalapril in symptomatic chronic heart failure: A dose comparison. Eur Heart $J$ 1998; 19: 481-489.

38. Hunt SA, Baker DW, Chin MH, Cinquegrani MP, Feldman AM, Francis GS, et al. ACC/AHA guidelines for the evaluation and management of chronic heart failure in the adult: Executive summary: A report of the American College of Cardiology/American Heart Association Task Force on Practice Guidelines (committee to revise the 1995 guidelines for the evaluation and management of heart failure). J Am Coll Cardiol 2001; 38: 2101-2113.

39. Xie HG, Kim BB, Wood AJ, Stein CM. Molecular basis of ethnic differences in drug disposition and response. Апnи Rev Pharmacol Toxicol 2001; 41: 815-850.

40. Alexander JH. Clinical trials in Japan and United States. Am Heart J 2004; 147: 200-201.

41. Guidelines for drug treatment of arrhythmias (JCS 2004). Circ J 2004; 68: $981-1053$.

42. Members of Sicilian Gambit. The search for novel antiarrhythmic strategies. Jpn Circ J 1998; 62: 633-648. 